Review

\title{
The Role of CXCLI2-CXCR4 Signaling Pathway in Pancreatic Development
}

\author{
Keiichi Katsumoto 1,2,3 and Shoen Kume 2,3凶 \\ 1. The Danish Stem Cell Center (DanStem), University of Copenhagen, 3B Blegdamsvej, Copenhagen N, DK-2200, Denmark. \\ 2. Department of Stem Cell Biology, Institute of Molecular Embryology and Genetics (IMEG), Kumamoto University, Honjo 2-2-1, Ku- \\ mamoto 860-0811, Japan; \\ 3. The Global COE 'Cell Fate Regulation Research and Education Unit,' Kumamoto University, Honjo 2-2-1, Kumamoto 860-0811, Japan.
}

$\bowtie$ Corresponding author: skume@kumamoto-u.ac.jp.

( ) Ivyspring International Publisher. This is an open-access article distributed under the terms of the Creative Commons License (http://creativecommons.org/ licenses/by-nc-nd/3.0/). Reproduction is permitted for personal, noncommercial use, provided that the article is in whole, unmodified, and properly cited.

Received: 2012.07.02; Accepted: 2012.09.13; Published: 2013.01.12

\begin{abstract}
Chemokine (C-X-C motif) receptor 4 (CXCR4) is the receptor for chemokine (C-X-C motif) ligand 12 (CXCLI2, also known as stromal derived factor-I, SdfI). CXCR4, a protein consisting 352 amino acids, is known to transduce various signals such as cell differentiation, cell survival, cell proliferation, cell chemotaxis and apoptosis [I, 2]. The expression of CXCR4 is observed in embryonic stem cells, blood cells, haematopoietic stem cells, endothelial cells, angioblasts and smooth muscle cells [3-9]. The CXCLI2-CXCR4 signaling pathway has very important roles in the embryonic development. Mutant mice for CXCLI2 or CXCR4 genes showed lethality due to defects in neurogenesis, angiogenesis, cardiogenesis, myelopoiesis, lymphopoiesis and germ cell development [10-13]. Recently, we reported that CXCLI2-CXCR4 signaling pathway has a crucial role in regional specification of the gut endoderm during early development [14]. Here, we would like to focus on the role of CXCLI2-CXCR4 signaling pathway in pancreatic development and summarize recent findings of its role in the induction of the pancreatic progenitor cells.
\end{abstract}

Key words: CXCL12, CXCR4, signaling pathway

\section{An overview of early pancreas develop- ment}

The earliest pancreatic marker gene, pancreatic and duodenal homeobox $1(P d x 1)$ starts to be expressed in the pre-pancreatic endoderm at the 9-somite stage (ss), corresponding to embryonic day 8.5 (E8.5) in the mouse and at 8 ss in the chick [14-17]. $P d x 1$ is also expressed in the stomach and duodenal endoderm. The pancreas is derived from the dorsal and ventral endoderm, which give rise from two distinct origins. In the mouse, the pancreatic bud emerges from E9.5. Fate map studies revealed that while the dorsal pancreas progenitor cells originated at the 3-6 somite levels at 7-9 ss in the mouse embryo, the ventral pancreatic progenitors are closely associated with hepatic progenitors and that they originates at the 1 ss at the lateral endoderm posterior to the anterior intestinal portal (AIP) lip [18]. Later on, at 3-4 ss, they were observed at the outer side at the AIP lip.

In the chick, the dorsal pancreas progenitors were first observed near the hensen's node at late gastrula stage (stage 5), which then migrate to the 3-6 somite levels at $6 \mathrm{ss}$, then to the 4-7 somite levels at 8 ss [19]. The ventral pancreas progenitor cells were first observed lateral to the 2 somite level at $10 \mathrm{ss}$, which then migrate to a site lateral to the 4 somite level at 17 ss [20] (Figure 1).

All mature pancreatic cell types are derived from the common pancreatic progenitors, which expresses $P d x 1$ and pancreas specific transcription factor $1 a$ (Ptf1a) and SRY-box containing gene 9 (Sox9) [21-23]. Gu 
et al. have shown that PDX1-expressing precursor cells give rise to all pancreas cell types, namely, the endocrine, exocrine and duct cells by Cre / LoxP lineage tracing experiments (Figure 2) [23].

Analyses of the $P d x 1$ homozygous null mutations have shown that PDX1 have a key role in the pancreas development: the initial pancreatic bud formation and early insulin and glucagon expression are observed, but further development is arrested. However, overexpression of $P d x 1$ did not induce an ectopic pancreas in the pre-stomach or pre-intestine region in the chick embryo, therefore, Pdx1 alone does not act as a pancreatic determinant [24].

Activin and fibroblast growth factor 2 (Fgf2, also known as bFGF), which are secreted from notochord, are candidate factors for maintaining the early pancreatic related genes through repression of sonic hedgehog (Shh) expression in the pre-pancreatic endoderm [25]. However, the notochord signals (Activin and Fgf2) are considered as permissive signals rather than instructive signals, because the notochord does not induce the pancreas in the posterior non-pancreatic endoderm [26]. Next, the dorsal aorta replaces the notochord and comes into close contact with the pre-pancreas endoderm and gives the signals that enhance the pancreas differentiation. The dorsal aorta is necessary for dorsal pancreas development, but the molecular nature of these signals is still unknown. The induced $\beta$ cells produce vascular endothelial growth factor (VEGF), then attract blood vessels, and potentiate insulin expression [27].

On the other hand, the ventral pancreas does not need the notochord signals for further development. The pre-ventral pancreas region is away from the notochord (Figure 1E). When the notochord is removed surgically, the pancreas related genes are down regulated in the dorsal pancreas but not in the ventral pancreas $[18,20,26,28]$.

The ventral pancreas and liver reside at the AIP lip region very near to each other [18, 20, 26, 28]. It is proposed that they derived from bipotential progenitor cells in the ventral foregut endoderm. One of the key molecules from the cardiac mesoderm to induce the liver is FGF. When the FGF signaling was suppressed in the ventral foregut region, pancreas developed in the expense of the liver [29-31].

\section{Dorsal}

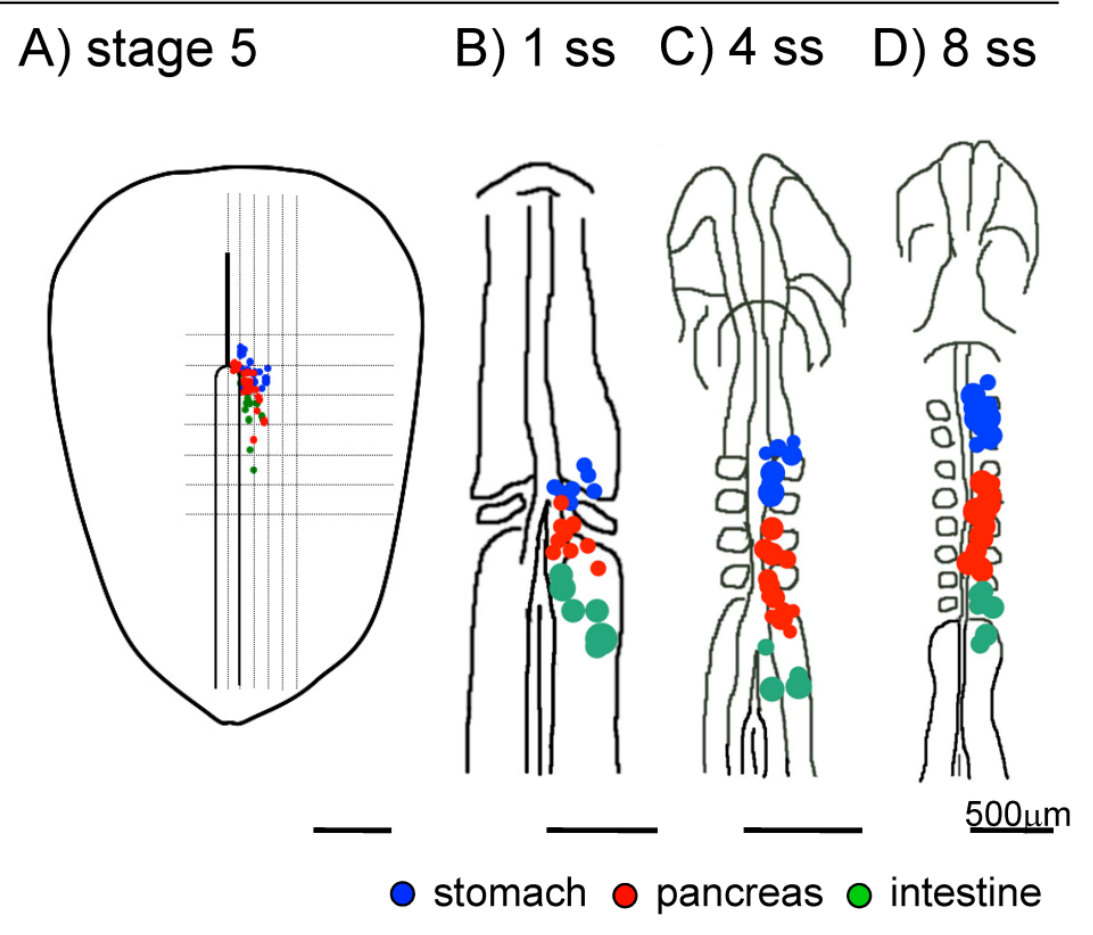

Ventral
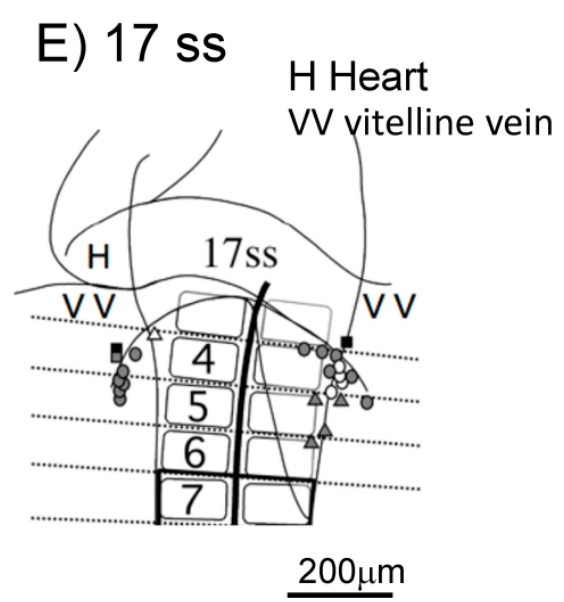

ventral pancreas

ventral pancreas or intestine

$\triangle$ intestine, stomach

$\triangle$ intestine

bile duct

- bile duct, liver

Figure I. Fate maps of the early chick endoderm. A-D: Fate maps of the dorsal pancreas at different embryonic stages. Blue: The pre-stomach endoderm, red: pre-pancreas endoderm, green: pre-intestine endoderm. E: Fate map of the ventral pancreas. The pre-ventral pancreas resides at the 4 -somite level in the lateral endoderm near the vitelline vein at 17 ss. A: stage 5 , B: I ss, C: 4 ss, D: 8 ss E: 17 ss. Scale bar: A-D $500 \mu \mathrm{m}, \mathrm{E} 200 \mu \mathrm{m}$. 


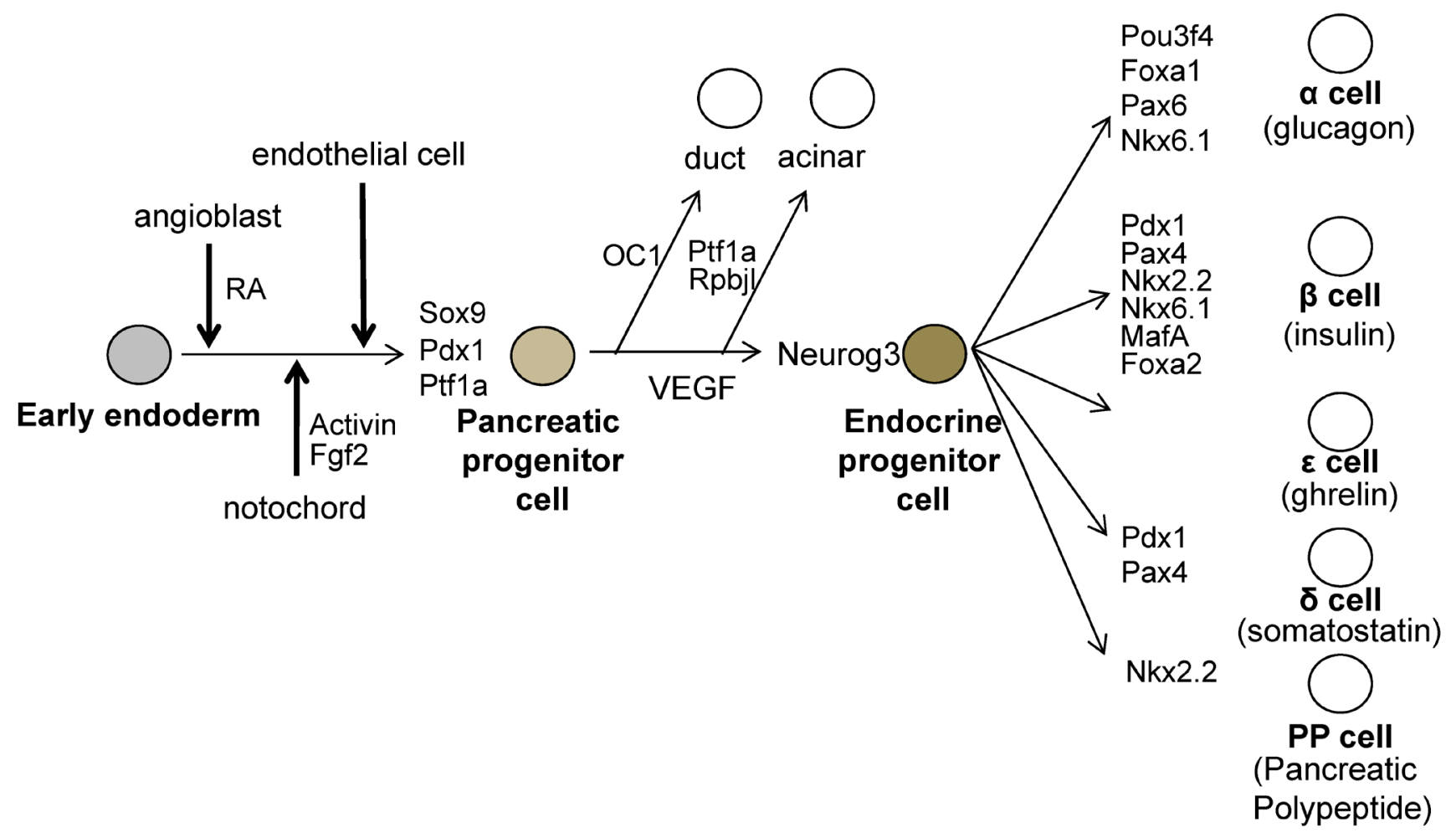

Figure 2. The molecules involved during pancreatic development. The pre-pancreatic endoderm receives the $P d x I$ inducing signals from the angioblasts (One of the candidate signal is Retinoic Acid; RA). And next, Pdxl-expressing pre-pancreas endoderm receives the pancreatic maintenance signals sequentially from the notochord, then from the endothelial cells. The pancreatic progenitor cells are induced and these cells express PdxI, Sox 9 and Ptfla. All endocrine cells are generated from neurogenin 3 (Neurog3)- expressing endocrine progenitor cells, which then differentiate into endocrine cells expressing specific set of transcription factors.

\section{Role of the chemokine signals in pancre- atic development: regionalization of the early endoderm}

It was reported that activin and bFGF signals from the notochord are permissive signals for pancreatic development, but up to date, there is little information on the inductive signal, by which the pre-pancreas region is defined in the early endoderm. Previously, we have reported in a fate map study, which was based on transplant experiments, that regional-specific endodermal fates are specified in a chronological order of the stomach (SRY-box containing gene 2; Sox2 expression, $2 \mathrm{ss}$ ), intestine (caudal type homeobox $1 ; C d x A$ expression, $5 \mathrm{ss}$ ) and then pancreas ( $P d x 1$ expression, $8 \mathrm{ss}$ ) (Figure 3) [19, 32].

More recently, we revealed that the angioblasts have a crucial role in inducing the $P d x 1$ expression in the pre-pancreas region in the chick embryo. We found that $\mathrm{Cxcl12}$ is expressed in the endoderm and Cxcr4 is expressed in the angioblasts, which reside in the lateral plate mesoderm and the early endoderm, before it starts to express $P d x 1$ [14].

At 8 ss, $P d x 1$ starts to be expressed in the in- ter-somite endoderm in the pre-pancreas region (4-7 somite levels). Later, the $P d x 1$ expression extends to the endoderm underneath the somites. This $P d x 1$ expression pattern correlates closely with the spreading of the angioblasts at between the somites, as well as with the migration of the endoderm. The $P d x 1$-expressing pre-pancreas endoderm lies in contact with the angioblasts, which express angioblast markers such as LIM domain only 2 (Lmo2), T-cell acute lymphocytic leukemia 1 (Tal1), kinase insert domain protein receptor (Kdr, also known as Flk1) and CD34 antigen (Cd34) [14].

The angioblasts reside in the pre-stomach and pre-pancreas, but not in the pre-intestine region at early somitic stages, coinciding with pancreas inducing signals existing in the pre-stomach and pre-pancreas region at these stages [19]. The angioblasts begin to appear around the pre-stomach region at $4 \mathrm{ss}$, in contact with the endoderm. However, these angioblasts do not have the ability to induce the $P d x 1$ expression in the pre-stomach region. Since the pre-stomach is already committed to express Sox 2 (stomach marker gene) at $2 \mathrm{ss,} \mathrm{it} \mathrm{lost} \mathrm{the} \mathrm{competency}$ to the $P d x 1$ inducing signals emitted from the angio- 
blasts. Similarly, the angioblasts appear at the pre-intestine region at $10 \mathrm{ss}$, but are not able to induce $P d x 1$ expression in the pre-intestine region. Since the pre-intestine region is already committed to express $C d x A$ (intestine marker gene) at $5 \mathrm{ss,} \mathrm{it} \mathrm{lost} \mathrm{the} \mathrm{com-}$ petency to the $P d x 1$ inducing signals emitted from the angioblasts (Figure 3) [14, 19].

Ectopic overexpression of $\mathrm{Cxcl12}$ in the early endoderm attracted the Lmo2-expressing cells (angioblast), which then induced the $P d x 1$ and Sox9 expressing pancreatic progenitors and resulted in generating a bigger pancreas and expanded insulin-expressing area. Conversely, inhibition of CXCR4 by AMD3100 treatment disturbed the migration of angioblasts to the proximity of the endoderm and delayed the timing of the aorta formation. This caused a reduction in $P d x 1$ - and Sox9-expressing pancreatic progenitors and led to a smaller pancreas with a smaller insulin-expressing area. These results suggest that the correct timing that angioblasts come in contact with the endoderm is a key to induce the $P d x 1$ expression (the induction of a pancreatic fate) in the pre-pancreas region. And this timing is finely controlled by CXCL12-CXCR4 signaling pathway (Figure 3) [14].

A 2 ss
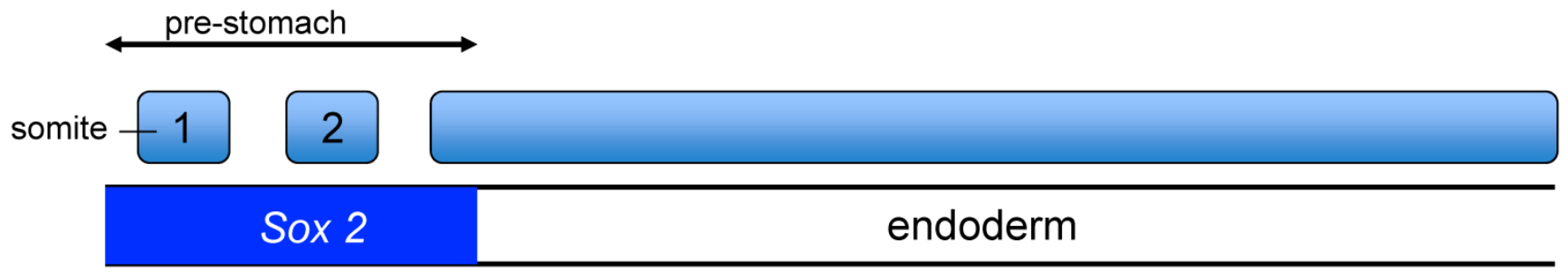

B $\quad 5$ ss

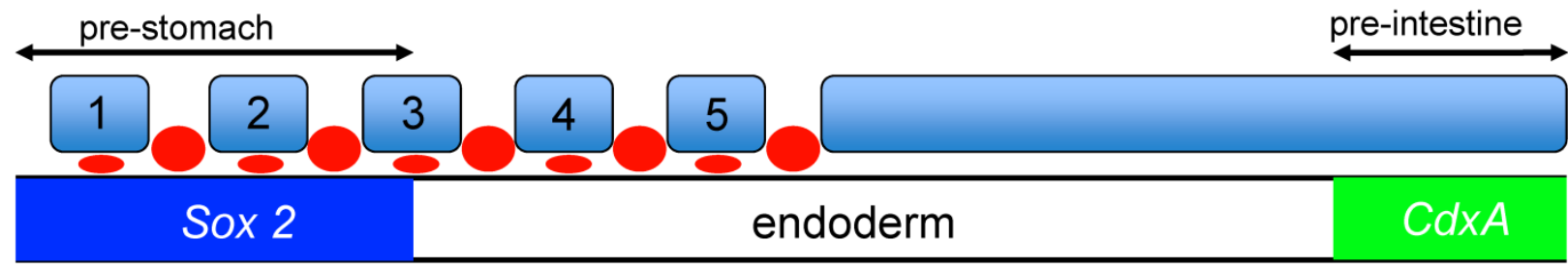

C $\quad 10 \mathrm{ss}$

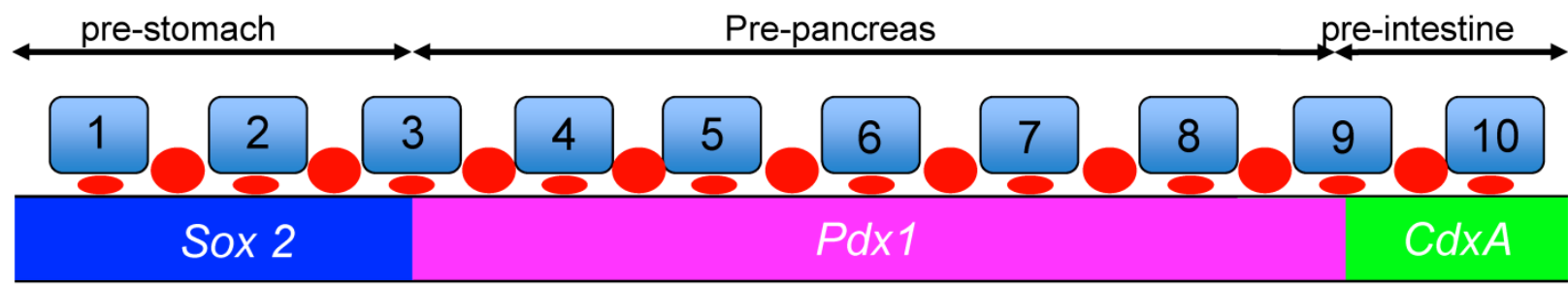

Figure 3. Competency of the endoderm for the $P d x I$-inducing signals emitted from the angioblasts. A-C Regional specific endodermal fates are specified in a chronological order: the stomach (Sox2, 2ss), intestine ( $C d x A, 5 s s)$ and then pancreas (PdxI, 8ss). The angioblast emit $P d x I$ inducing signals. At 5ss, although the angioblasts reside at the pre-stomach region, they cannot induce $P d x I$ expression in the pre-stomach endoderm because the pre-stomach endoderm is already determined to express Sox 2 at 2 ss, and they lost the competency to respond to $P d x I$ inducing signals from the angioblasts at 5 ss. The pre-pancreatic endoderm has the competency to respond to signals from the angioblasts. On the other hand, the pre-intestine endoderm is determined to express $C d x A$ at 5 ss, and lost their competency to respond to $P d x I$-inducing signals from the angioblasts at the time they reach the pre-intestine at I0ss. 


\section{The role of the chemokine signals in the early pancreatic differentiation}

The CXCL12-CXCR4 signaling pathway has key roles in the vascular formation. Cxcl12 or Cxcr4 mutant embryos die before birth. And there are defects in the vasculature of the gastrointestinal and nerve systems [11-13, 33]. It is known that CXCL12 and CXCR4 are expressed in the mouse islets. And it is also known that CXCR4 is expressed in the proliferating duct epithelium in the regenerating pancreas of non-obese diabetic (NOD) mice engineered to express interferon (IFN)- $\gamma$ driven by the rat insulin promoter (RIP). In the IFN- $\gamma$ transgenic mice, the inhibition of CXCR4 function caused the defects in cell proliferation and increases apoptosis in the pancreatic duct cells [34]. In the RIP-CXCL12 transgenic mice, the development of diabetes by the streptozotocin treatment is rescued. In this report, it is also revealed that six hours after streptozotocin administration, a pro-proliferative signal, phospho-Akt, was activated in the $\alpha$ cells, but not in the $\beta$ cells. In the control mice, $\beta$ cells were replaced by the $\alpha$ cells two weeks after streptozotocin treatment. In contrast, in the RIP-CXCL12 transgenic mice, many $\beta$ cells persisted or regenerated [35]. These data suggest that a cross-talk mechanism might exist between the $\alpha$ and $\beta$ cells. It is reported that CXCL12 shows cytoprotective effects on the $\beta$ cells, and controls the $\beta$ cell survival not only through the pro-survival kinase Akt, but also through the activation and stabilization of $\beta$-catenin/transcription factor 7 like 2, T cell specific, HMG box (TCF7L2) transcriptional activators [36]. It is also reported that CXCL12 expression is re-induced in the $\beta$ cells by treatment with streptozotocin, thapsigargin and cytokines in the adult islet and in the rat insulinoma INS-1 cells. CXCR4 is expressed in both the $\alpha$ and $\beta$ cells. The paracrine signal of CXCL12 from $\beta$ cells activates in $\alpha$ cells the protein kinase Akt and induces the production of prohormone convertase (PC) $1 / 3$ and glucoincretin hormone glucagon-like peptide-1 (GLP-1). CXCL12 also shows anti-apoptotic activity. Finally, GLP-1 signal from $\alpha$ cells, in combination with CXCL12 are shown to control the growth and viability of $\beta$ cells [37]. Recently, it was also reported that Epithelial progenitor 1 (EP1), which is related to the uPAR/CD59/Ly-6/snake toxin family that contains cysteine-rich domains, was detected in the duct cells of regenerating pancreas of the IFN- $\gamma$ transgenic mice, but not in the embryonic stages, or in the wild type mice. Flow cytometry analysis revealed that the EP-1 positive cells in the above INF- $\gamma$ transgenic mice, also expressed CXCR4. In the RIP-CXCL12 transgenic mice, upon cerulein treatment EP-1 were expressed in the epithelial cells in a scattered manner throughout the pancreas. These data suggest that EP1-expressing cells respond to CXCL12 and are involved in epithelial cell expansion. Until now, there is not much information on how EP1 regulates the pancreatic regeneration through the CXCL12-CXCR4 axis. Further analysis is required to identify the function of EP1 in the pancreatic regeneration process [38]. CXCL12 also control the morphological branching in the developing pancreas [39]. However, the defect in branching was observed in the ventral but not in the dorsal pancreas in the Cxcl12 mutant mice [39]. In the zebrafish, inhibition of $c x c l 12 b$ and $c x c r 4 a$ caused the duplication of pancreas [40]. This is compatible with a scenario in which CXCL12-CXCR4 axis affects the migration of the angioblasts, which induced the $P d x 1$ expression in early endoderm in the chick embryo. This discrepancy can be explained by the difference in the size between the chick and zebrafish embryos. We hypothesize that because the zebrafish embryo is much smaller, the cxcr4a- and Lmo2-positive mesodermal cells (angioblasts), which originated from the lateral plate mesoderm, do not have to travel a long distance to reach the site at the pre-pancreatic endoderm border compared to the case of the chick embryo. However, without guidance by the CXCL12-CXCR4 signaling, the migration of the angioblasts to the correct region (pre-pancreatic region) in the zebrafish might be disturbed, thereby generating a duplicated pancreas. Another possibility is that in smaller size embryos (for example, zebrafish), at conditions without the CXCL12-CXCR4 signaling, a lower number of angioblasts might have reached the pre-pancreas endoderm, compared with the wild type embryos. This resulted in the induction of $P d x 1$ in a patchy fashion in the endoderm, which then yielded a duplicated pancreas. Furthermore, cxcr4a is also important for the migration of endoderm cells themselves [40,41]. Therefore, pancreas formation might also be affected in the CXCR4 inhibited embryos. In contrast, in the chick embryo, because of its large size, Cxcr4 and Lmo2-positive mesodermal cells (angioblasts) have to cover a larger distance to contact the pre-pancreas region at a correct timing. We hypothesize that when lacking the CXCL12-CXCR4 signaling guidance in the chick embryos, the directed migration fails to occur properly (Figure 4) [14]. It is also reported that endothelial cells are generated from cxcr $4 a$ positive anterior mesoderm and $c x c l 12 b$ is expressed in the endoderm underlying the lateral aorta in the zebrafish embryos. It is also reported that Cxcl12b-Cxcr4a signaling has crucial roles in the lateral aorta formation in the zebrafish [42]. This results support our observations in the early chick embryos [14]. 


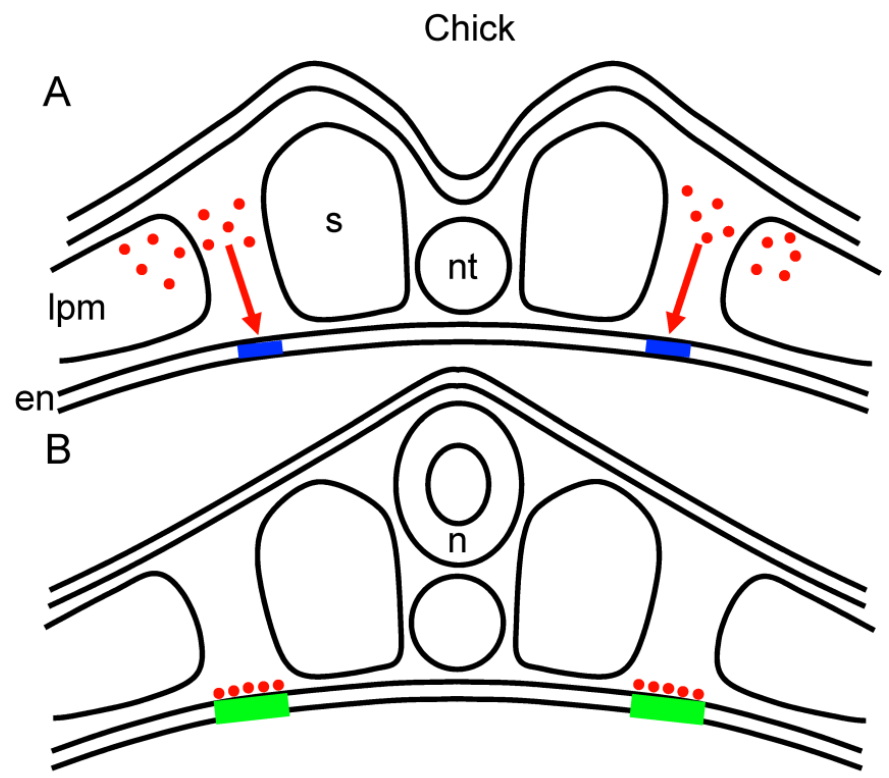

- CXCR4+ angioblast

- CXCL12+ endoderm

- Pdx1+ endoderm
Ipm: lateral plate mesoderm

nt: notochord

s: somite
Zebrafish

$A^{\prime}$

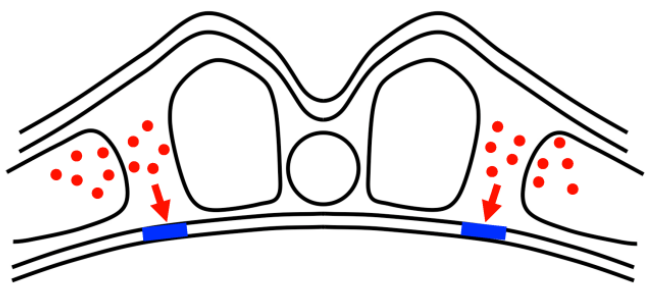

B'

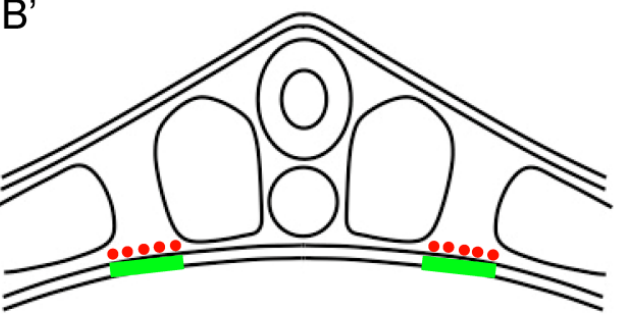

$100 \mu \mathrm{m}$

Figure 4. The size of the embryo affects the migration distance of the angioblasts from the lateral plate mesoderm to the endoderm. A-B: The angioblasts at the lateral plate mesoderm migrate to the correct side of the endoderm, being attracted by the CXCR I 2-CXCR4 signaling. Since the chick embryo is bigger than the zebrafish, the angioblasts in the chick embryos have to travel a longer distance from the lateral plate mesoderm to the endoderm, compared to that in the zebrafish $(A)$. In the zebrafish, the angioblasts migrate to the endoderm through a comparatively shorter distance $\left(A^{\prime}\right)$. After arriving at the endoderm, the angioblast induce $P d x I$ expression in the pre-pancreas region (B,B'). Scale bar: $100 \mu \mathrm{m}$.

\section{Conclusion}

We revealed the mechanism by which the early pancreas regionalization is controlled in the early endoderm. CXCL12-CXCR4 signaling pathway controls the spatiotemporal migration of the angioblasts, which has the pancreatic inducing activity. CXCL12-CXCR4 signaling does not directly induce the expression of $P d x 1$ (Pancreas) in the early pancreas, but rather through an indirect way, by controlling the migration of the angioblasts. The understanding of the nature of normal pancreatic development is a key to succeed the regeneration of $\beta$ cells from pluripotent stem cells to treat the diabetes mellitus [43, 44].

\section{Competing Interests}

The authors have declared that no competing interest exists.

\section{References}

1. Ganju RK, Brubaker SA, Meyer J, Dutt P, Yang Y, Qin S, et al. The alpha-chemokine, stromal cell-derived factor-1alpha, binds to the transmembrane G-protein-coupled CXCR-4 receptor and activates multiple signal transduction pathways. J Biol Chem. 1998; 273: 23169-75.
2. Schober A, Karshovska E, Zernecke A, Weber C. SDF-1alpha-mediated tissue repair by stem cells: a promising tool in cardiovascular medicine? Trends Cardiovasc Med. 2006; 16: 103-8.

3. Zernecke A, Schober A, Bot I, von Hundelshausen P, Liehn EA, Mopps $B$, et al. SDF-1alpha/CXCR4 axis is instrumental in neointimal hyperplasia and recruitment of smooth muscle progenitor cells. Circ Res. 2005; 96: 784-91.

4. Yamaguchi J, Kusano KF, Masuo O, Kawamoto A, Silver M, Murasawa $\mathrm{S}$, et al. Stromal cell-derived factor-1 effects on ex vivo expanded endothelial progenitor cell recruitment for ischemic neovascularization. Circulation. 2003; 107: 1322-8.

5. Nelson TJ, Faustino RS, Chiriac A, Crespo-Diaz R, Behfar A, Terzic A. CXCR4+/FLK-1+ biomarkers select a cardiopoietic lineage from embryonic stem cells. Stem Cells. 2008; 26: 1464-73.

6. Moll NM, Ransohoff RM. CXCL12 and CXCR4 in bone marrow physiology. Expert Rev Hematol. 2010; 3: 315-22.

7. Kollet O, Spiegel A, Peled A, Petit I, Byk T, Hershkoviz R, et al. Rapid and efficient homing of human CD34(+)CD38(-/low)CXCR4(+) stem and progenitor cells to the bone marrow and spleen of NOD/SCID and NOD/SCID/B2m(null) mice. Blood. 2001; 97: 3283-91.

8. Gupta SK, Lysko PG, Pillarisetti K, Ohlstein E, Stadel JM. Chemokine receptors in human endothelial cells. Functional expression of CXCR4 and its transcriptional regulation by inflammatory cytokines. J Biol Chem. 1998; 273: 4282-7.

9. Broxmeyer HE. Chemokines in hematopoiesis. Curr Opin Hematol. 2008; 15: $49-58$

10. Cencioni C, Capogrossi MC, Napolitano M. The SDF-1/CXCR4 axis in stem cell preconditioning. Cardiovasc Res. 2012; 94: 400-7.

11. Nagasawa T, Hirota S, Tachibana K, Takakura N, Nishikawa S, Kitamura $\mathrm{Y}$, et al. Defects of B-cell lymphopoiesis and bone-marrow myelopoiesis in mice lacking the CXC chemokine PBSF/SDF-1. Nature. 1996; 382: 635-8.

12. Tachibana K, Hirota S, Iizasa H, Yoshida H, Kawabata K, Kataoka Y, et al. The chemokine receptor CXCR4 is essential for vascularization of the gastrointestinal tract. Nature. 1998; 393: 591-4. 
13. Zou YR, Kottmann AH, Kuroda M, Taniuchi I, Littman DR. Function of the chemokine receptor CXCR4 in haematopoiesis and in cerebellar development. Nature. 1998; 393: 595-9.

14. Katsumoto K, Kume S. Endoderm and mesoderm reciprocal signaling mediated by CXCL12 and CXCR4 regulates the migration of angioblasts and establishes the pancreatic fate. Development. 2011; 138: 1947-55.

15. Yoshida T, Murata K, Shiraki N, Kume K, Kume S. Analysis of gene expressions of embryonic stem-derived Pdx1-expressing cells: implications of genes involved in pancreas differentiation. Dev Growth Differ. 2009; 51: 463-72.

16. Jonsson J, Carlsson L, Edlund T, Edlund H. Insulin-promoter-factor 1 is required for pancreas development in mice. Nature. 1994; 371: 606-9.

17. Offield MF, Jetton TL, Labosky PA, Ray M, Stein RW, Magnuson MA, et al. PDX-1 is required for pancreatic outgrowth and differentiation of the rostral duodenum. Development. 1996; 122: 983-95.

18. Miki R, Yoshida T, Murata K, Oki S, Kume K, Kume S. Fate maps of ventral and dorsal pancreatic progenitor cells in early somite stage mouse embryos. Mech Dev. 2012; 128: 597-609.

19. Katsumoto K, Fukuda K, Kimura W, Shimamura K, Yasugi S, Kume S. Origin of pancreatic precursors in the chick embryo and the mechanism of endoderm regionalization. Mech Dev. 2009; 126: 539-51.

20. Matsuura K, Katsumoto K, Fukuda K, Kume K, Kume S. Conserved origin of the ventral pancreas in chicken. Mech Dev. 2009; 126: 817-27.

21. Kawaguchi Y, Cooper B, Gannon M, Ray M, MacDonald RJ, Wright CV. The role of the transcriptional regulator Ptf1a in converting intestinal to pancreatic progenitors. Nat Genet. 2002; 32: 128-34.

22. Seymour PA, Freude KK, Tran MN, Mayes EE, Jensen J, Kist R, et al. SOX9 is required for maintenance of the pancreatic progenitor cell pool. Proc Natl Acad Sci U S A. 2007; 104: 1865-70.

23. Gu G, Dubauskaite J, Melton DA. Direct evidence for the pancreatic lineage: NGN3+ cells are islet progenitors and are distinct from duct progenitors. Development. 2002; 129: 2447-57.

24. Grapin-Botton A, Majithia AR, Melton DA. Key events of pancreas formation are triggered in gut endoderm by ectopic expression of pancreatic regulatory genes. Genes Dev. 2001; 15: 444-54.

25. Hebrok M, Kim SK, Melton DA. Notochord repression of endodermal Sonic hedgehog permits pancreas development. Genes Dev. 1998; 12: 1705-13.

26. Kim SK, Hebrok M, Melton DA. Notochord to endoderm signaling is required for pancreas development. Development. 1997; 124: 4243-52.

27. Lammert E, Cleaver O, Melton D. Induction of pancreatic differentiation by signals from blood vessels. Science. 2001; 294: 564-7.

28. Tremblay KD, Zaret KS. Distinct populations of endoderm cells converge to generate the embryonic liver bud and ventral foregut tissues. Dev Biol. 2005; 280: 87-99.

29. Zaret KS. Genetic programming of liver and pancreas progenitors: lessons for stem-cell differentiation. Nat Rev Genet. 2008; 9: 329-40.

30. Zaret KS, Grompe M. Generation and regeneration of cells of the liver and pancreas. Science. 2008; 322: 1490-4.

31. Deutsch G, Jung J, Zheng M, Lora J, Zaret KS. A bipotential precursor population for pancreas and liver within the embryonic endoderm. Development. 2001; 128: 871-81.

32. Katsumoto K, Shiraki N, Miki R, Kume S. Embryonic and adult stem cell systems in mammals: ontology and regulation. Dev Growth Differ. 2010; 52: 115-29.

33. Nagasawa T, Tachibana K, Kishimoto T. A novel CXC chemokine PBSF/SDF-1 and its receptor CXCR4: their functions in development, hematopoiesis and HIV infection. Semin Immunol. 1998; 10: 179-85.

34. Kayali AG, Van Gunst K, Campbell IL, Stotland A, Kritzik M, Liu G, et al. The stromal cell-derived factor-1alpha/CXCR4 ligand-receptor axis is critical for progenitor survival and migration in the pancreas. J Cell Biol. 2003; 163: 859-69.

35. Yano T, Liu Z, Donovan J, Thomas MK, Habener JF. Stromal cell derived factor-1 (SDF-1)/CXCL12 attenuates diabetes in mice and promotes pancreatic beta-cell survival by activation of the prosurvival kinase Akt. Diabetes. 2007; 56: 2946-57.

36. Liu Z, Habener JF. Stromal cell-derived factor- 1 promotes survival of pancreatic beta cells by the stabilisation of beta-catenin and activation of transcription factor 7-like 2 (TCF7L2). Diabetologia. 2009; 52: 1589-98.

37. Liu Z, Stanojevic V, Avadhani S, Yano T, Habener JF. Stromal cell-derived factor-1 (SDF-1)/chemokine (C-X-C motif) receptor 4 (CXCR4) axis activation induces intra-islet glucagon-like peptide-1 (GLP-1) production and enhances beta cell survival. Diabetologia. 2011; 54: 2067-76.

38. Kritzik MR, Lago CU, Kayali AG, Arnaud-Dabernat S, Liu G, Zhang YQ, et al. Epithelial progenitor 1, a novel factor associated with epithelial cell growth and differentiation. Endocrine. 2010; 37: 312-21.
39. Hick AC, van Eyll JM, Cordi S, Forez C, Passante L, Kohara H, et al. Mechanism of primitive duct formation in the pancreas and submandibular glands: a role for SDF-1. BMC Dev Biol. 2009; 9: 66.

40. Nair S, Schilling TF. Chemokine signaling controls endodermal migration during zebrafish gastrulation. Science. 2008; 322: 89-92.

41. Mizoguchi T, Verkade H, Heath JK, Kuroiwa A, Kikuchi Y. Sdf1/Cxcr4 signaling controls the dorsal migration of endodermal cells during zebrafish gastrulation. Development. 2008; 135: 2521-9.

42. Siekmann AF, Standley C, Fogarty KE, Wolfe SA, Lawson ND. Chemokine signaling guides regional patterning of the first embryonic artery. Genes Dev. 2009; 23: 2272-7.

43. Kume S. Stem-cell-based approaches for regenerative medicine. Dev Growth Differ. 2005; 47: 393-402.

44. Kume S. The molecular basis and prospects in pancreatic development. Dev Growth Differ. 2005; 47: 367-74. 